Pesquisando sobre as representações do cientista durante o curso de Graduação em Biologia: uma estratégia didática visando à formação de professores de Ciências

Researching on the representations of the scientist during of the grade in Biology: a didactic strategy aiming at training to teaching Sciences

\author{
Cássia Santos Camillo ${ }^{1}$ \\ Maikel da Silva Ferreira Luiz ${ }^{1}$ \\ Tatyane do Socorro Soares Brasil ${ }^{1}$ \\ Wanessa Barbosa Santana ${ }^{1}$ \\ Esther Campagna Bertazzoni ${ }^{1}$ \\ Maria Aparecida de Souza Perrelli ${ }^{2}$
}

${ }_{1}$ Graduado do Curso de Biologia da Universidade Católica Dom Bosco.

2 Doutora em Educação para a Ciência, Professora da Universidade Católica Dom Bosco. cidaperrelli@yahoo.com.br. 


\section{Resumo Abstract}

A epistemologia do professor pode influenciar as suas ações como educador.

Atentando para essa questão, o Curso de Biologia da Universidade Católica Dom Bosco, por meio da disciplina de Estágio Supervisionado, desenvolveu uma atividade de pesquisa/reflexão, envolvendo os acadêmicos e alunos do ensino fundamental, com objetivos de

(1) conhecer as concepções de alunos sobre os cientistas, (2) cotejá-las com as concepções dos acadêmicos e (3) refletir

sobre o papel dessas concepções nas

ações como educador em ciências. $\mathrm{O}$ trabalho realizado mostrou que os alunos do ensino fundamental, assim como os acadêmicos, conservavam uma imagem estereotipada do cientista e, por conseqüência, da própria ciência. O cientista é

visto como uma pessoa do sexo masculino, um inventor e descobridor que executa suas atividades nos laboratórios. A partir dessas constatações, e por meio de discussões acompanhadas do docente da disciplina de Estágio Supervisionado,

os acadêmicos foram estimulados a refletir e rever suas próprias concepções de ciência e a compreender a importância do professor na (re) construção dessas concepções nos alunos.

\section{Palavras-chave}

concepção de cientista concepção de Ciência formação do professor
The epistemology of the teacher can influence their actions as an educator. Paying attention to this issue, the Course of Biology at the Universidade Católica Dom Bosco, through the discipline of Supervised Stage, developed an activity of research/reflexion, involving college studentes and students of elementary school, with goals of (1) understand the students conceptions on the scientists, (2) compare them with the conceptions of college students and (3) reflect on the role of these concepts in the actions as an educator in science. The work showed that students of elementary school, as well as college students, took a stereotyped image of the scientist and, consequently, the science itself. The scientist is seen as a person man, an inventor and discoverer who runs its activities in laboratories. Based on these findings, and through discussions with the teaching of the discipline of Supervised Stage, the college students were encouraged to reflect and review their own conceptions of science and understand the importance of the teacher in (re) construction of these concepts in students.

\section{KEY WORDS}

scientist conception science conception

training teacher 


\section{InTRODUÇão}

A ciência como instituição é alggo recente, e tem adquirido, até certo ponto, as características das profissões fechadas. "Cientista" é um termo que foi usado pela primeira vez por Whewell, em 1840, em Philosophy of Inductive Sciences, e pode ser visto no seguinte trecho: "realmente precisamos de um nome para desionnar o cultivador da ciência em geral. Eu me inclinaria a chamar-Ihe de cientista" (BERNAL, 1989, tradução nossa).

Para Bourdieu (1983), o cientista só existe no contexto de uma crença coletiva nos fundamentos produzidos e supostos no seu próprio Campo. Segundo o autor, a ciência é um Campo Social como outro qualquer, com suas relações de força e monopólios, suas lutas e estratégias, seus interesses e lucros, mas onde todas estas invariantes são revestidas de formas específicas. No Campo Científico, toda a prática está orientada para a aquisição da autoridade científica (transmutada em prestígio, reconhecimento, celebridade, etc), e todas as estratégias visam assegurar a posição daqueles que definem o que pode ser considerado como verdadeiramente científico ou não. É no interior dos Sistemas de Ensino, de acordo com Bourdieu $(1982 ; 1983)$ que ocorre a retroalimentação do Campo Científico, pois é nesse ambiente que se inculca o habitus científico nos novatos. Nos Sistemas de ensino o futuro homem da ciência incorpora matrizes de percepção, de apreciação e de ação próprias do Campo Científico, o que o conduzirá a uma adesão ao Campo e Ihe dará conđições de participação na luta para que ali permaneça.

Kuhn (1998, p. 220) define uma "comunidade científica" como um conjunto de pessoas que partilham um paradiogma e que "foram submetidos a uma iniciação profissional e a uma educação similares, numa extensão sem paralelos na maioria das outras disciplinas. Neste processo, absorveram a mesma literatura técnica e dela retiraram muitas das mesmas lições". Para Kuhn (1998) os membros de uma comunidade científica vêm a si próprios e são vistos pelos outros como os únicos responsáveis pelo treino de seus sucessores 
para a adesão profunda a uma maneira particular de ver o mundo e praticar a ciência. A educação científica é, portanto, uma iniciação relativamente dogmática a uma tradição preestabelecida de resolver problemas.

A imagem que as pessoas leigas têm da ciência e do cientista estão bem distantes das abordagens dos filósofos e sociólogos. O que se observa entre os leigos, na atualidade, é uma percepção equivocada da ciência, associada a uma visão empírico-indutivista, utilitária e antropocêntrica da atividade científica. A ciência é vista como um trabalho individual, capaz de produzir um conhecimento verdadeiro, imutável, a-histórico e neutro. O que comumente se vê, tanto na mídia quanto nos lirros didáticos, é uma ciência executada por uma classe especial de pessoas, trabalhando com estranhos aparatos em Iaboratórios, envolvidas com cálculos e demonstrações.

Tais representações também estão presentes nos alunos dos diversos níveis de ensino, e não são facilmente transformadas pela escola. Isso se deve a pelo menos dois motivos. Primeiro porque os conceitos e teorias formulados pelos alunos são construtos lógicos que gozam de uma estabilidade de difícil mudança. Isso implica a necessidade de o professor conhecê-las a fim de dar condições para que os alunos possam problematizá-las, re-elaborá-las e construir novas concepções à luz de uma outra lógica - a lógica cientifica, distinta daquela utilizada nas suas formulações primeiras. O segundo motivo refere-se à epistemologia do professor como indutora da formação de representações sobre a ciência nos alunos. Harres (1999) é um dos autores que considera que as concepções dos professores em relação à natureza da ciência são uma importante variável da imagem da ciência construída nos alunos durante a vida escolar. Partindo dessa consideração o autor aponta a necessidade de conhecer melhor essas concepções dos docentes e identificar formas de sua evolução rumo a uma visão mais "adequada” da ciência (as aspas querem ressaltar que o autor considera que não há uma única e correta visão de ciência) e a reflexão sobre os currículos formativos dos professores que, ao que parece, têm propiciado a permanência de visões equivocadas da ciência. 
A correlação entre a epistemologia do professor e a sua prática, assinalada por Harres, parece não ser tão simples como se anuncia. De acordo com Abd-El-Khalick et al. (1998) há uma intrincada interação entre as concepções do professor sobre a natureza da ciência, os aspectos envolvendo sua formação, as pressões do sistema escolar, as experiências prévias dos alunos, etc., mas nem sempre a aquisição de concepções adequadas sobre ciência, pelo professor, implica uma meIhor performance em relação à construção dessas concepções nos seus alunos. Essa situação é também discutida em Porlán et al. (1998) quando assinalam que existe um conjunto de concepções metadisciplinares que constituem verdadeiras cosmovisões ou epistemologias pessoais e que influem e afetam o conhecimento e a prática dos professores.

Tendo como hipótese e preocupação a persistência de percepções equirocadas a respeito da ciência, tanto nos alunos de ensino médio e fundamental como também nos universitários, e visando a conhecê-las e problematizá-las, foi desenvolvida uma atividade com acadêmicos do oitavo (último) semestre do Curso de Biologia da Universidade Católica Dom Bosco-UCDB, no intuito de conhecer as visões que alunos do ensino fundamental têm sobre o "cientista", além de refletir sobre as visões dos acadêmicos e contribuir para a formação do futuro professor pesquisador para uma prática crítico-reflexiva.

Este texto deriva de um artigo escrito por um grupo de acadêmicos de Biologia participantes da atividade mencionada como exigência para cumprimento da caroga horária da disciplina de Estáoio Supervisionado. A versão ora apresentada toma como ponto de partida alguns trechos do artigo original no qual os autores relatam os resultados da investigação realizada com os alunos do ensino fundamental. Além disso, acrescenta discussões sobre os achados da pesquisa e insere os encaminhamentos dados durante a disciplina de Estágio Supervisionado, provocados pela atividade descrita, e objetivando provocar nos acadêmicos reflexões sobre as suas próprias concepções e sobre a importância destas na sua formação e na sua prática como futuro professor. 


\section{As ATIVIDADES PROPOSTAS, AS QUESTÕES E REFLEXÕES SUSCITADAS}

A atividade foi realizada no ano de 2005 durante a disciplina de Estágio Supervisionado do Curso de Biologia da Universidade Católica Dom Bosco-UCDB e percorreu dois momentos. O primeiro transcorreu no período em que os acadêmicos estagiaram como docentes e consistiu em uma pesquisa na qual se obteve se obteve informações sobre as visões de "cientista" de alunos das séries finais do ensino fundamental. Partindo dos resultados obtidos, o segundo momento ocorreu ao longo das aulas da disciplina de Estágio Supervisionado nas quais foram provocadas reflexões, com os acadêmicos do Curso, sobre (1) as visões de ciência dos acadêmicos estagiários, no início e no final do Curso, (2) o sistema escolar como formador dessas visões e (3) a importância de levar em conta, no planejamento de ensino, as idéias prévias dos alunos acerca do tema, a fim de favorecer a possível mudança.

\subsection{A pesquisa sobre As CONCEPÇÕes de “Cientista” dos alunOs}

A pesquisa foi realizada com alunos de $5^{\mathrm{a}}$ a $8^{\mathrm{a}}$ séries do Ensino Fundamental da Escola General Osório, em Campo Grande, Mato Grosso do Sul. Foi solicitado aos alunos que expressassem na forma de texto e/ou de desenhos aquilo que pensavam a respeito do cientista. Não foram definidas categorias para análise dos textos a priori. Estas foram definidas à medida que se procedia à leitura de cada um, procurando identificar as palaøras e/ou as idéias-chaves. Já para os desenhos, estabeleceu-se uma lista prévia de categorias de análise; contudo, a lista manteve-se aberta a incorporar outras categorias que porventura surgissem durante a interpretação das imagens registradas pelos alunos.

Dos 31 desenhos produzidos, nove foram de alunos da $5^{\mathrm{a}}$ série, dez da $6^{\mathrm{a}}$, cinco da $7^{\mathrm{a}}$ e sete da $8^{\mathrm{a}}$. Foram produzidos 58 textos fazendo referência aos cientistas. Destes, 10 foram escritos por alunos da $5^{\mathrm{a}}$ série, nove da $6^{\mathrm{a}}, 19$ da $7^{\mathrm{a}}$ e 20 da $8^{\mathrm{a}}$.

Com exceção de um desenho, os demais representaram o cientista como pessoa do sexo masculino. Sobressaíram as representações destes usando jaleco, óculos e outros acessórios de proteção. Também 
foram retratados como carecas, usando barba e bigode.

A representação do cientista como pessoa do sexo masculino parece estar associada à história da construção da profissão de pesquisador, que inicia, em todo o mundo, com pessoas do sexo masculino (o que, de resto, é extensiøo à história da maioria das profissões), expandindo-se, muito recentemente, para as pessoas do sexo feminino.

Nos textos produzidos pelos alunos, houve a caracterização dos cientistas principalmente como inventores, descobridores, estudiosos e inteligentes. Um número menor de alunos considerou os cientistas como pesquisadores, criativos, espertos, curiosos, confiáveis. Um deles mencionou o cientista como ateu.

Um número expressivo de textos (aproximadamente 40\%, em média) mencionou que os cientistas eram pessoas que beneficiavam à humanidade por intermédio de suas descobertas e invenções. Poucos foram os que fizeram menção aos malefícios à humanidade, decorrentes de algumas descobertas científicas.

Essas representações do cientista como descobridor de algo associado à atividade benemérita podem ser entendidas com o apoio de Bernal (1989) e Mayr (1998). Segundo o primeiro, foi e ainda é disseminada a idéia de que o progresso do conhecimento estaria associado, exclusivamente, ao fruto do trabalho de grandes homens, deixando à margem as relações deste com os fatores econômicos e sociais. Bernal (1989, p. 43) afirma: "na história da ciência o mito dos 'grandes homens' foi mais longe do que na história política e social: muitas histórias da ciência não são de fato senão relatos acerca dos grandes descobridores que vão se sucedendo em uma mais ou menos apostólica revelação dos segredos da natureza”. Já segundo Mayr (1998), o público leigo, influenciado pela visão de ciência transmitida pelos meios de comunicação, relaciona a atividade científica com novas descobertas. Assim, não é de estranhar que os alunos associem a figura do cientista com a de um inventor ou descobridor.

A abordagem feita por Mayr (1998) se fez notar na atividade realizada, uma vez que o período em que a pesquisa ocorreu foi contemplado quase que diariamente com notícias na mídia a respeito de 
novas descobertas científicas e tecnológicas relacionadas com a cura de doenças (por exemplo, pesquisas com células-tronco) e também à produção de alimentos (pesquisas com transgênicos). Esses acontecimentos podem ter influenciado os alunos a representarem os cientistas como pessoas relacionadas com pesquisas na área da saúde humana e com os benefícios que estas trazem à humanidade.

Além dessa área de conhecimento, a atividade do cientista abordada nos textos dos alunos foi, em sua maioria, associada à física e à química. As ciências da saúde aparecem em segundo lugar e fortemente relacionadas à cura de doenças. As áreas biológicas, especialmente a zoologia e a botânica figuram em terceiro lugar. Raras referências foram feitas às ciências humanas e sociais. Destas mencionou-se apenas a história e a arqueologia. As áreas tecnológicas foram igualmente pouco destacadas.

Nos desenhos dos alunos de todas as turmas, tal caracterização do cientista se confirma. As ciências naturais foram as mais representadas. Destas, a química foi apresentada com maior freqüência, destacando-se os desenhos de bancadas de laboratório contendo vidrarias (béquer e erlenmeyer), além de soluções em ebulição ou evaporação. Houve alguns desenhos de microscópios, fazendo referência às ciências biológicas. Um aluno desenhou uma cena de coleta de dados de campo. Outro representou um médico como cientista e outro mencionou que os professores também são cientistas.

Pode-se compreender essas representações recorrendo a Mayr (1998). O autor chama a atenção para o fato de que, durante muito tempo, a história da ciência foi contada segundo a história das ciências físicas, desconsiderando as demais áreas. Desse modo, muitos fisicistas, filósofos e historiadores da ciência consideraram que uma teoria científica só teria real valor quando provada matematicamente por métodos experimentais.

O fato de as ciências terem se orientado, por um longo período, segundo os parâmetros das ciências experimentais fez com que fosse justamente esta a imagem de ciência disseminada na sociedade. Ainda hoje a mídia recorre à imagem da atividade científica experimental, de modelo do ocidente, feita por pessoas do sexo masculino. Quando 
retratam mulheres, estas estão ligadas às ciências humanas. Assim sendo, é bastante provável que a imagem de cientista representada pelos alunos tenha sido adquirida no cotidiano de sua cultura, que permanece reforçando a visão de ciência experimental, valorizada e percebida como ciência, em detrimento de outras áreas do conhecimento.

\subsection{AS ATIVIDADES DE REFLEXÃO DOS ACADÊMICOS SOBRE SUAS PRÓPRIAS CONCEPÇÕES DE CIÊNCIA}

Após serem descritas as representações dos alunos do ensino fundamental sobre a atiøidade científica, o passo seguinte foi trazer para điscussão, na disciplina de Estágio Supervisionado, as seguintes questões: (1) Em que medida os resultados da pesquisa se aproximam ou se distanciam das representações de cientista e da ciência dos acadêmicos estagiários? (2) Qual a responsabilidade do professor e dos Sistemas de Ensino na (des)construção dessas representações? (3) O ensino de ciências, tal qual tem sido praticado, tem contribuído para a transformação dessas representações?

A decisão de discutir essas questões foi inspirada em Désautels (1989, p. 266) que aborda a necessidade de o professor integrar às estratégias pedagógicas "atividades que visam explicitamente a favorecer no aluno uma reflexão sobre seu próprio saber e seus modos de produção" (grifo nosso). Essa é uma condição para a tomada de consciência do seu modo de pensar e das eventuais diferenças que este pode ter de outros modos de pensar. Sem essa tomada de consciência o aluno não perceberá que existem outros tipos de conhecimento baseados em premissas epistemológicas e regras de produção diferentes das suas.

O início dessas reflexões foi favorecido pela comparação feita entre os desenhos produzidos pelos alunos do ensino fundamental e pelos acadêmicos estagiários, no ano de seu ingresso ao Curso (em 2002), por meio da qual pode-se constatar que havia grande proximidade entre as representações de cientista produzidas por ambos. Estar ciente disso foi o motor para a continuidade do processo de reflexão a respeito das implicações dessas visões dos futuros docentes no ensino de ciências. Esse momento foi sustentado por leituras de alguns 
textos sugeridos pelos acadêmicos e pela docente que conduzia a disciplina de Estágio Supervisionado. As discussões foram norteadas principalmente pelos seguintes textos: (1) Fernandez et al. (2002) em "Visiones deformadas de la ciencia transmitidas por la enseñanza" apresentam uma ampla revisão de literatura das pesquisas sobre a concepção do trabalho cientifico entre os professores, demonstrando que o ensino formal ou informal, inclusive o universitário, transmite implícita ou explicitamente visões deformadas da ciência (concepção empírico-indutivista e ateórica da atividade científica, visão rígida, exata, infalível, exclusivamente analítica do trabalho cientifico, visão aproblemática e ahistórica đa ciência, imagem acumulativa de crescimento linear dos conhecimentos, visão individualista e elitista e eminentemente masculina da ciência, uma imagem descontextualizada e socialmente neutra da ciência), e ressaltam a importância de (re)conhecê-las a fim de modificar a "epistemologia espontânea" do professorado, dado que ela pode se constituir um obstáculo capaz de bloquear as intenções de renovação do ensino das ciências; (2) Harres (1999), em "Concepções sobre a natureza da ciência", faz uma revisão das pesquisas sobre as concepções de professores em relação à natureza da ciência e conclui que predomina entre os docentes uma imagem empirista, e que estes passam aos alunos uma idéia de objetividade e infalibilidade do método científico, de veracidade absoluta e superioridade do conhecimento científico. $\mathrm{O}$ autor mostra, ainda, que pode haver correlação entre a concepção, no professor, sobre a natureza da ciência e a concepção de ensino: à concepção empirista sobre a natureza da ciência corresponde à concepção racionalista de ensino (com ênfase ao raciocínio lógico e as explicações corretas, um conhecimento acabado e verdadeiro) e, ao mesmo tempo, a uma concepção empirista (que enfatiza a observação e aplicação do método científico em sala de aula); (3) Porlán et al. (1998), em "Conocimiento profesional y epistemologia de Ios profesores II: estudios empíricos e conclusiones”, assinalam que nem sempre o fato de o professor ter concepções adequadas sobre a ciência implica uma melhor performance em relação à construção dessas concepções nos seus alunos, uma vez que existe um conjunto de concepções metadisciplinares funcionando como 
verdadeiras cosmovisões ou epistemologias pessoais do professor, influindo no seu conhecimento e na sua prática; (4) Reis e Galvão (2005), em "Controvérsias sócio-científicas e prática pedagógica de jovens professores”, chamam a atenção para o quanto é complexo e exigente o objetivo educacional de ensinar sobre a natureza da ciência; assinalam, ainda, que a preparação do professor para a concretização desta tarefa requer, dentre outros elementos, o questionamento e a discussão das suas concepções prévias acerca desta temática; (5) Bourdieu (1983), em "A economia das trocas simbólicas", discute as especificidades do campo científico ao mesmo tempo que o situa como um campo social como outro qualquer, com suas lutas entre a ortodoxia e a heterodoxia, um jogo de forças entre os pares-concorrentes pela aquisição de capital específico que lhe garanta a permanência no campo.

\section{Considerações finaIS}

As discussões foram bastante ricas e entrecortadas por exposições e reflexões dos acadêmicos sobre as imagens distorcidas que haviam construído ao longo do processo de escolarização. Ao final da atividade, os acadêmicos concluíram que a universidade não poderia ser apenas o locus de ensino e de aprendizagem de técnicas para a execução das tarefas de ensinar e pesquisar. Na sua tarefa formadora, a Universidade é também lugar no qual o graduando, futuro professor e/ ou pesquisador, construa uma visão de ciência que contemple os seus aspectos sociais, políticos, econômicos, epistemológicos e axiológicos. Essa visão favoreceria a atuação do professor e/ou pesquisador, de forma crítica, no jogo do Campo em que estiver inserido.

Acreditamos que a escola deve ser um dos lugares onde se ensina, além das ciências, também sobre as ciências, visando a construir, no aluno, uma visão da atividade científica como empreendimento humano, histórico, um campo onde há disputas, controvérsias e relações de poder, que é regido por normas e princípios éticos próprios. Cremos que dessa forma, estaremos contribuindo para formar uma imagem de ciência que atenta para as questões filosóficas e sociológicas que envolvem esse empreendimento. Espera-se, assim, que os alunos dos 
diversos níveis de ensino possam compreender e opinar criticamente acerca das questões que dizem respeito à ciência e à tecnologia e as suas relações com a sociedade e com o ambiente.

A atividade ora relatada sinaliza para a necessidade de incluir nos currículos formativos de professores das mais diferentes áreas, a problematização das idéias de ciência que eles possuem e transmitem, seja de forma oculta, seja explícita. A experiência da qual este texto resulta pretendeu caminhar nessa direção. Apresentou uma atividade, dentre tantas outras desenvolvidas durante o estágio curricular de docência, preocupadas com essa questão. Mostra, ainda, o potencial de um trabalho que coloca a pesquisa em ensino de ciências como conteúdo da disciplina de Estágio Supervisionado. Este trabalho, segundo avaliação dos acadêmicos envolvidos, constituiu-se numa oportunidade de "olhar-se no espelho e ver a história das imagens que ele reflete". O "espelho" mostrou a eles a importância de contemplar na formação do professor de ciências a discussão crítica sobre as origens das suas concepções de ciência e sobre o papel da escola na construção dessas concepções. Mostrou ainda que formar o professor para a atividade reflexiva inclui, dentre outros aspectos, dar condições para que ele possa pensar sobre as origens das certezas que orientam a sua prática, seja como aluno ou como docente, e para que possa enfrentar os desafios impostos quando é preciso mudá-las.

\section{REFERÊNCIAS}

ABD-EL-KHALICK, F; BELL, R. L.; LEDERMANN, N. G. The nature of science and instructional practice: making the unnatural natural. Science Education, Hoboken, New Jersey, v. 82, n. 4, p. 417-436, 1998.

BERNAL, J. D. Historia Social de la ciencia, 1, La ciencia en la historia. Barcelona: Ediciones Peninsula, 1989.

BOURDIEU, P. A economia das trocas simbólicas. São Paulo: Perspectiva, 1982.

BOURDIEU, P. O campo científico. In: ORTIZ, R. (Org.), FERNANDES, F. (Coord.). Pierre Bourdieu: Sociologia. São Paulo: Ática, 1983, p.122-155.

DÉSAUTELS, J. Développement conceptuel et obstacle épistemologique. In: BEDNARZ, N.; GARNIER, C. (Ed.). Construction des savoirs, obstacles et 
conflits. MontreaI: CIRADE,1989, p. 258-267.

FERNANDEZ, I.; GIL, D. ; CARRASCOSA, J. , CACHAPUZ, A. , PRAIA, J. Visiones deformadas de la ciencia transmitidas por la enseñanza. Enseñanza de las Ciencias, Barcelona, v. 20, n. 3, p. 477-488, 2002.

HARRES, J. B. S. Concepções sobre a natureza da ciência. 1999. Tese (Doutorado em Educação) - Pontifícia Universidade Católica do Rio Grande do Sul. Porto Alegre, 1999.

KUHN, T. S. A estrutura das revoluções científicas. 5. ed. São Paulo:

Perspectiva, 1998.

MAYR, E. O desenvolvimento do pensamento biológico. Brasília: UnB, 1998.

PORLÁN, R.; RIVERO, A.; MARTÍN DEL POZO, R. Conocimiento profesionaI y epistemologia de los profesores II: estudios empíricos e conclusiones. Enseñanza de las Ciencias, Barcelona, v. 16, n. 2, p. 271-289, 1998.

REIS, P.; GALVÃO, C. Controvérsias sócio-científicas e prática pedagógica de jovensprofessores. Investigações em Ensino de Ciências. Porto Aleogre, $\nabla .10$, n. 2, ago. 2005. Disponível em: <http://www.if.ufross.br/public/ensino>. Acesso em: 6 jan. 2006. 